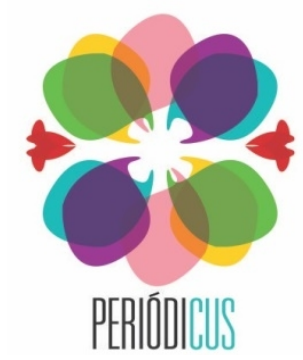

ISSN: 2358-0844

n. $16, v .3$

out.2021-dez.2021

p. $133-155$

\title{
Masculinidade, trabalho e modo de vida:
}

\section{a identidade do mecânico automotivo}

\author{
(Masculinity, work and lifestyle: \\ the identity of the automotive mechanic) \\ (Masculinidad, trabajo y modo de vida: \\ la identidad del mecánico automotriz)
}

\section{Laura Senna Ferreira ${ }^{1}$}

RESUMO: Neste artigo, busca-se analisar a identidade do mecânico automotivo a partir da construção da masculinidade e do modo de vida que singulariza essa categoria de ofício. Observa-se que a ocupação dos mecânicos, mais do que uma posição na divisão sociotécnica do trabalho, diz respeito a um estilo, um modo de ser e pensar, no qual a exibição da masculinidade é aspecto crucial do teatro cotidiano, que ensina uma profissão ao mesmo tempo que ensina um determinado modo de ser homem. Tendo como base estudo realizado na cidade de Porto Alegre (RS), problematiza-se as dinâmicas que se estabelecem na interface entre trabalho, carros e um modelo de "masculinidade hegemônica".

PALAVRAS-CHAVE: Masculinidade. Trabalho. Mecânico automotivo.

Abstract: This article aims to analyze the identity of the automotive mechanic from the idea of masculinity and the way of life that characterizes this occupation. Beyond a quota inscribed in the sociotechnical division of labor, the auto mechanic profession is associated with a way of living and thinking entangled with the social proposition of showing masculinity teaching both a profession and a model of being man. Considering the context of Porto Alegre (RS), this study discusses the dynamics between work, cars, and a model of "hegemonic masculinity."

Keywords: Masculinity. Work. Automotive mechanic.

Resumen: En este artículo se propone analizar la identidad del mecánico automotriz desde la construcción de la masculinidad y el modo de vida que distingue a esta categoría profesional. La ocupación de los mecánicos más allá de una posición en la división sociotécnica del trabajo refiere a un estilo, una forma de ser y de pensar, en la que la exhibición de la masculinidad es un aspecto crucial del teatro cotidiano, que enseña una profesión y a la vez un modo de ser hombre. A partir de un estudio que se llevó a cabo en la ciudad de Porto Alegre (Brasil), se discuten las dinámicas en la interfaz entre trabajo, automóvil y un modelo de "masculinidad hegemónica".

Palabras clave: Masculinidad. Trabajo. Mecánico automotriz.

1 Doutora em sociologia pela Universidade Federal do Rio de Janeiro (UFRJ). Professora no Programa de PósGraduação em Ciências Sociais da Universidade Federal de Santa Maria (UFSM). E-mail: laurasennafe@hotmail.com. 


\section{Introdução}

Este trabalho analisa a relação entre ofício e masculinidade. Trata-se de compreender o processo de constituição da identidade do mecânico automotivo, da qual faz parte um universo de saberes, um modo de vida e uma versão da masculinidade.

Os mecânicos lançam mão do repertório clássico que define histórica e culturalmente a “masculinidade hegemônica”. A gramática que utilizam para definição do perfil dos que integram o grupo indica uma fronteira delineada acerca dos pressupostos de hombridade necessários para o exercício da profissão, que vão desde a força, passando pela despreocupação estética até o apreço pelo automobilismo, um esporte considerado para "machos”.

A oficina mecânica é um espaço de trabalho e de sociabilidade masculina. Trata-se de um território de masculinidade, povoado por corpos laborais marcadamente másculos, que utilizam marcas como barba, regata, exposição de músculos, piadas de conteúdo sensual, gosto por carros e motores, exibição de força, entre outros ícones que definem um território masculino.

Ser mecânico é sinônimo de ser homem, posto as poucas exceções de participação das mulheres no segmento. Essa é uma atividade que, no passado, era aprendida basicamente pelas mãos de outros homens, quais sejam, pais, parentes ou vizinhos encarregados de transmitir o ofício, os valores, posturas na vida e versões de gênero. Hoje, esse papel é ocupado também por instituições, como as escolas formativas, a exemplo do Senai Automotivo², que continuam sendo um espaço de socialização masculina.

Este trabalho tem como base entrevistas, inserções etnográficas e investigações documentais que ocorreram entre 2010 e 2013, na cidade de Porto Alegre (RS). A constituição do grupo investigado se baseou, por um lado, na rede social indicada pelos interlocutores e, por outro, na inclusão independente de instituições com reconhecido impacto no segmento.

Para o estudo, considerou-se as entrevistas realizadas com mecânicos e/ou proprietários de oficinas, em seus locais de trabalho ou residência, e com gestores e membros de entidades vinculadas à indústria da reparação. A experiência etnográfica ocorreu junto às oficinas independentes, que são as que não têm vínculos com as concessionárias, bem como nos espaços de sociabilidade dos mecânicos, como no caso do autódromo de Tarumã (RS).

Este artigo se inicia pelo debate teórico acerca da masculinidade. Na sequência, ocupa-se da análise do caso dos mecânicos no que diz respeito à construção de uma masculinidade que se combina com a definição do ofício. Por fim, apresenta-se as principais conclusões da pesquisa.

2 O Senai Automotivo de Porto Alegre forma trabalhadores para a indústria da reparação automotiva. A escola teve origem no final de 1999 e conta, atualmente, com uma parceria de cooperação técnica com as principais montadoras, oferecendo cursos de iniciação profissional, aperfeiçoamento profissional e técnico. 


\section{Aspectos teóricos}

Propõe-se, aqui, o desafio de analisar a noção de masculinidade, a partir da concepção de habitus, de Pierre Bourdieu, e da perspectiva de "masculinidade hegemônica", de Robert Connell. Consideram-se aspectos das críticas que se dirigem a tais perspectivas e que são fundamentais por trazer a pluralidade e as diferentes formas históricas, culturais e territoriais de construção da masculinidade.

Num tensionamento interpretativo dessas formulações, Butler (2003) discute os sistemas de classificação de gênero e o modo pelo qual se nomeia e normatiza essas relações. Tais sistemas classificatórios são decisivos na performatividade de gênero e capazes de produzir violências e violações, vulnerabilidades e precariedades corporais, como no caso de corpos privados de determinados direitos. A violência implicada nas ações reguladoras - no sentido de uma heterossexualidade compulsória - é produzida diariamente desde as "primeiras socializações”, quando são engendradas zonas de normatividades estruturadas.

Para Bourdieu (2007), as estruturas de gênero são definidas pelo habitus: 1. capaz de produzir práticas classificáveis; e 2. capacidade de apreciar tais práticas através de julgamentos. O habitus organiza ações que se tornam constitutivas de um estilo de vida, quer dizer, de um conjunto de preferências distintivas que se exprimem em mobiliários, vestuário, linguagem e hexis corporal. O habitus envolve disposição geral, duradoura e transferível, o que significa estrutura estruturada (opus operatum) e estrutura estruturante (modus operandi), que traduzem as diferenças objetivas das condições de existência de dada posição social.

A partir da concepção de habitus, assim como da noção de masculinidade hegemônica, não se espera ofuscar as críticas que tais conceitos sofrem pela proximidade com concepções estruturalistas, ao contrário, busca-se dimensionar as singularidades. Todavia, não se renuncia a um olhar sociológico para as dimensões que permanecem de modo estrutural na organização da vida social.

Do ponto de vista da crítica - mas não propriamente da negação dessas formulações -, Butler (2003) indica que a luta queer envolve o direito simbólico, concreto e legal de reconhecimento da pluralidade não tradicionalmente estruturada, o que significa o direito que outros corpos têm de ter visibilidade. Nos estudos de Butler, o corpo emerge como espaço que sofre os impactos do poder institucional - e os regimes de violências legais associados -, constituindo-se, portanto, como instância política. Se o corpo é vulnerabilizado, é também por meio dele que as pessoas podem se rebelar e se manifestar. Nesse particular, o corpo não é somente expressão de uma estrutura, pois também pode ser instrumento de rebelião contra essa estrutura - contra o habitus, no sentido de Bourdieu. 
As individualidades e heresias são importantes, mas elas têm

limites bem precisos: da cultura do próprio tempo e da classe não se sai a não ser para entrar no delírio e na ausência de comunicação. Assim como a língua, a cultura oferece ao indivíduo um horizonte de possibilidades latentes - uma jaula flexível e invisível dentro da qual se exercita a liberdade condicionada de cada um. (GINZBURG, 2006, p. 20-21)

Nessa "liberdade condicionada", residem certas originalidades que "não parecem resultado de influências externas passivamente recebidas”. (GINZBURG, 2006, p. 23) Dessa forma, põe-se em cena o tema da resistência, quer dizer, a possibilidade que a cultura tem de não se tornar reflexo de determinado padrão. Há, na maioria das vezes, uma pluralidade de vivência social que precisa ser considerada. (CERTEAU, 2008)

Os indivíduos não apenas aceitam, mas também refutam. No cotidiano, há singularidades e há uma "arte de fazer”, que é lugar da criatividade e da liberdade. Por isso, Certeau (2008) afirma que é preciso observar as operações dos usuários, visto que o “uso” é fundamental. Não há apenas uma recepção a qual se sujeitam os indivíduos de forma passiva e dócil: há outros resultados além de inculcação, sendo de extrema importância considerar as diferentes versões de heresias subversivas.

Neste sentido, observa-se que não há uma única masculinidade, pelo contrário, há uma pluralidade delas, contudo, boa parte delas é balizada por uma masculinidade hegemônica. Essa masculinidade lança mão do sexo biológico - a dimensão anatômica - como suporte para construção do gênero, que envolve atributos de valores e de condutas, posto que, historicamente, o sexo passou a fundar a diferença de gênero.

Recentemente, a noção de que têm surgido novas masculinidades passa pela forte entrada das mulheres no mercado de trabalho, redefinições de papéis de gênero, formas diferenciadas de construção do corpo, que oportunizam outras subjetividades, identidades de gêneros e sexualidades possíveis: bissexuais, drag queens, travestis, transexuais, homossexuais, heterossexuais e outros que se combinam e que não se enquadram em tipologias. Essas modalidades de experienciar a condição masculina questionam o núcleo da identidade de gênero e a acepção de que a heterossexualidade constituí a subjetividade dos homens. (COSTA, 2006)

A literatura tem discutido a ideia de uma crise de masculinidade, sendo crise concebida como conflito identitário, a partir de um modelo de identidade de gênero, que passa pela redefinição do papel de pai, marido, amante, trabalhador e cidadão, sendo que aquele que não se adapta é tratado como desviante da normalidade. A masculinidade hegemônica ainda se coloca como ideal de dignidade masculina, apesar de todos os abalos que têm sofrido tais versões, e é associada ao machismo, virilidade, heterossexualidade, patriarcado, posição dominante do 
homem, distanciamento emocional e agressividade. As identidades de gênero são poderosas, passando por definir gestos, comportamentos, modos de vestir, de falar, desejos afetivos e sexuais para homens e mulheres. Essas identidades tendem a estar em consonância com o sexo biológico em decorrência da socialização que dificulta o desempenho da singularidade, todavia, apesar de impostas pela socialização, não se trata de identidades fixas. Por serem ensinadas e negociadas, são mutáveis e podem ser bem diferentes. (COSTA, 2006)

Tal construto tem se baseado em ideais pouco condizentes com a experiência real dos homens, apesar de serem balizadas por eles. Parte desses compostos idealizados acerca do masculino podem ser observados na sistematização a seguir.

\section{Masculinidade hegemônica/homem ideal}

Não demonstra sofrimento; não chora; forte; ativo nas relações sexuais; domina o espaço público; coragem; virilidade; provedor; destemido; agressivo; musculoso; controle das emoções; ter quantas mulheres for possível; violento; homofóbico; papel ativo; ativo na conquista das mulheres; responsável; poderoso; autoconfiante; machista; heterossexual; arredio à sensibilidade; sedutor; gosta de beber; gosto por esporte violento; frequentador de bares; gosto por carros; come carne/churrasco; dominador da mulher e da prole; sexo forte; varão; fálico; competitivo; exerce poder sobre as mulheres; belicoso; trabalhador; racional...

Fontes consultadas: Costa (2006); Louro (2001) e Connell e Messerschmidt (2013).

Por outro lado, há as concepções que tratam de novos modelos de masculinidade, envolvendo possibilidades como as indicadas a seguir: sensibilidade; exercício de tarefas domésticas; participação na educação dos filhos; exercício de profissões consideradas femininas; admitir ganhar menos que as companheiras; admitir falha no intercurso sexual; identidades sexuais alternativas; preocupação com a saúde, estética e roupas; homossexuais; bissexuais; drag queens; travestis; transexuais; negar lugar de provedor. (COSTA, 2006; CONNELL; MESSERSCHMIDT, 2013; LOURO, 2001)

Apesar das possibilidades de outras subjetividades, verifica-se que se mantém a força dos protótipos de "machão", modelo naturalizado que define uma essência da condição masculina, à qual se associa atitudes, modos e gostos próprios de uma sociedade que opera por meio de uma "heterossexualidade compulsória", construindo padrões de masculinidade que imobilizam e engessam, não reconhecendo que o ser masculino pode estar muito além ou muito aquém dos estereótipos. (LOURO, 2001) 
A ênfase na multiplicidade da masculinidade é parte das críticas dirigidas ao conceito de masculinidade hegemônica de Connell (1987), para quem a masculinidade hegemônica - em detrimento das periféricas (masculinidades concorrentes) - passa pelo patriarcado, que pressupõe a superioridade masculina em relação às mulheres. O hegemônico é aquele que dicotomiza com os ideais de feminilidade, associada à delicadeza, bondade, obediência, caridade, maternidade, sensibilidade e suavidade.

A partir de estudos sobre gênero, a masculinidade passou a ser discutida, com destaque para os Estados Unidos, na década de 1970. Parte desses estudos tratou a masculinidade no plural, rompendo com a “diferenciação sexual que contrapõe masculino-feminino, macho-fêmea e que se estende para a vida social definindo o privado - feminino, mulher - e o público masculino, homem”. (HONÓRIO, 2011, p. 4) Desconstrói-se a naturalização do masculino a partir do corpo, indicando que são construções de um determinado momento histórico e contexto social e cultural.

O movimento feminista, desde fins dos anos 1960, questiona firmemente o patriarcado como instituição da organização da família e referência para as relações sociais. Do mesmo modo, defende a emancipação da mulher na esfera doméstica, conjugal, social, educacional e sexual, reivindicando direitos: sufrágio, aborto, ter ou não filhos, igualdade salarial, cargo, políticas públicas (saúde, delegacias...), sexualidade, participação política, autonomia, combinar vida pessoal e profissional, entre outros. Nos anos 1980, intensificaram-se as investigações sobre masculinidade, incluindo as pesquisas sobre gays. Os estudos definitivamente passaram a considerar o gênero - “diferenças percebidas entre os sexos” - como relações de poder assimétricas. (SCOTT, 1995)

Os Estudos Queer trazem um novo momento de inflexão ao questionarem os compostos binários - muitos dos quais balizaram a própria ação feminista com base num "sujeito estável” (BUTLER, 2003) -, chamando atenção para o horizonte da sexualidade e avançando na desconstrução dos essencialismos presentes nas categorias sexo e gênero -, pois tanto o segundo como o primeiro são percebidos como construções. Assim, a partir dessa perspectiva, não existem determinações nem da ordem da cultura nem de ordem biológica. Observar as dinâmicas contextuais e flutuantes que envolvem o desejo e a sexualidade é considerado mais relevante do que a preocupação acerca de uma suposta identidade de gênero.

A respeito da masculinidade hegemônica, é provável que poucos homens a adotem, mas ela é normativa. A forma mais honrosa de ser homem exige que todos se posicionem perante ela. É também tal concepção que legitima a subordinação das mulheres através de inúmeros “mecanismos de hegemonia”. (CONNELL; MESSERSCHMIDT, 2013) Dos diferentes estudos, 
a obra de Connell tem um lugar crucial a partir do conceito de masculinidade hegemônica por lançar mão da noção de hegemonia de Antonio Gramsci.

As masculinidades são distintas, passando por recortes de região, classe, etnia e geração em diferentes períodos históricos. Connell e Messerschmidt (2013, p. 249) consideram que as críticas ao conceito de masculinidade hegemônica vieram na esteira da ideia do "kit de ferramentas pós-estruturalista”, que acusou a noção de masculinidade hegemônica de naturalização, essencialismo e homogeneização por, supostamente, não reconhecer as “masculinidades de protesto”. Os autores consideram parte dessas críticas cruciais para revitalizar o conceito original, contudo, reafirmam a concepção de masculinidade hegemônica. Eles vão arguir que:

a masculinidade não é uma entidade fixa encarnada no corpo ou nos traços da personalidade dos indivíduos. As masculinidades são configurações de práticas que são realizadas na ação social e, dessa forma, podem se diferenciar de acordo com as relações de gênero em um cenário social particular. (CONNELL; MESSERSCHMIDT, p. 250)

As masculinidades são sempre relacionais, transversalizadas por divisões, "relações complexas de aderência e rejeição”. (CONNELL; MESSERSCHMIDT, p. 251)

O modelo de masculinidade pode ser pouco real, mas expressa ideais, sentidos, fantasias e desejos, sendo os homens tanto cúmplices como resistentes a esse modelo. A hegemonia impõe-se em relação às mulheres e em relação a outros homens. Defendendo o uso do conceito, afirma-se que “a prática social humana cria relações de gênero na história. O conceito de masculinidade hegemônica embute uma visão histórica dinâmica do gênero na qual é impossível apagar o sujeito”. (CONNELL; MESSERSCHMIDT, 2013, p. 259)

O padrão dominante de masculinidade está constantemente sujeito à contestação: mulheres que questionam o patriarcado; homens com masculinidades alternativas; novas relações de poder; contrato conjugal entre pessoas do mesmo sexo, entre outros. Verifica-se que o gênero é relacional, ocorrendo em relação com a feminilidade - mães, esposas, parceiras sexuais, namoradas, colegas de classe. Assim sendo, o gênero passa por diferentes arenas que impactam na reputação masculina entre os pares: famílias, organizações, corporações, comunidades, mídias, esporte etc.

É importante que o conceito de masculinidade hegemônica observe um entendimento mais holístico das relações de gênero e que reconheça a agência dos grupos subordinados, ou seja, que o conceito considere menos a masculinidade e mais a dinâmica de gêneros. Os "titulares de uma masculinidade hegemônica” podem tentar modernizar as relações de gênero e 
remodelar as masculinidades, trazendo a possibilidade de pensar em outras versões da masculinidade.

\section{Mecânica como espaço para homens e oficina como território de masculinidade}

A pesquisa etnográfica, num espaço tão masculino como o da oficina mecânica, é um desafio. Desde que a sociabilidade em torno do automóvel é um assunto para homens, faltava esse “conhecimento espontâneo” (FIGLIUZZI, 2008) que se espera que todos os homens tenham sobre carros. Para driblar o problema, assistiu-se às corridas da Fórmula $1^{3}$, procurou-se ler a revista Quatro Rodas ${ }^{4}$, foi acompanhada a programação do Auto Esporte ${ }^{5}$, bem como assistiu-se às corridas de carro no autódromo de Tarumã .

A dimensão de gênero foi incorporada na reflexão metodológica da pesquisa. Foi preciso conhecer e lidar com a fama envolvendo a sexualidade dos mecânicos, uma espécie de senso comum preconceituoso, que transforma o mecânico em um sujeito rude de natureza incivilizada ${ }^{7}$.

Os cuidados que membros das instituições do setor e os próprios mecânicos aconselhavam a tomar, no sentido de evitar os possíveis “abusos”/assédios, não eram recomendações decorrentes do simples fato dos nossos interlocutores serem homens, mas, sobretudo, pelo fato de serem mecânicos. Era a própria atividade que os classificava/estigmatizava como um grupo que poderia colocar em risco a pesquisadora/mulher.

Com relação ao horizonte intersecional envolvendo os diferentes atores, observa-se que os mecânicos interlocutores desta pesquisa são, na sua maioria, homens brancos de classe popular. Do ponto de vista geracional, o grupo inclui tanto os mais jovens - acostumados a lidar com as novas tecnologias eletrônicas - como os mais velhos - aqueles que, na era fordista, aprenderam a "fazer fazendo" numa época que o automóvel era muito mais mecânico do que eletrônico. No caso dos mecânicos que praticam automobilismo e/ou preparam carros de corrida,

3 Os campeonatos de Fórmula 1, organizados pela Federação Internacional de Automobilismo (FIA), têm início em 1950 e são resultantes de uma reformulação dos Grandes Prêmios europeus, disputados no início do século XX. O Brasil e a Alemanha (ambos com 8 títulos) estão, atrás da Inglaterra (com 9 títulos), na lista dos países que mais conquistaram campeonatos. Três de nossos títulos foram conquistados por Ayrton Senna, três deles por Nelson Piquet e dois por Emerson Fittipaldi.

4 A revista Quatro Rodas, primeira revista brasileira de automóveis, é publicada pela Editora Abril desde 1960. Trata-se de uma revista mensal, de circulação nacional, que aborda temas relacionados à indústria automotiva de modo geral.

5 O Auto Esporte é um programa da Rede Globo que traz uma série de informações sobre o setor automobilístico. O programa, desde 1999, vai ao ar durante 30 minutos todos os domingos de manhã.

6 O autódromo internacional de Tarumã, em Viamão, foi inaugurado em 1970.

7 A imagem do mecânico como um homem extremamente sexualizado é frequentemente representada nos programas de entretenimento da televisão brasileira. Exemplo recente foi o famoso personagem Pascoal (Reynaldo Gianecchini), da novela Belíssima, que atraia todas as mulheres da vizinhança da oficina. Pascoal era quase analfabeto, bonito, ingênuo e imoral. Não são poucas as cenas nas quais as famílias brasileiras riram quando Safira (Claudia Raia), uma mulher que traia o marido, beijava-o e chamava de "seu mecânico sujo e indecente" ao mesmo tempo. 
não se altera o perfil de classe, uma vez que, nos casos em questão, trata-se de um automobilismo popular e não aquele associado aos grandes circuitos de corrida. Assim, no que diz respeito à dimensão classe e gênero, esse corresponde a um grupo relativamente homogêneo. No que concerne à questão geracional, verifica-se uma multiplicidade de idades, entretanto, do ponto de vista da relação do ofício com a masculinidade, essa multiplicidade não produz uma diversidade equivalente, uma vez que os velhos deixam de herança aos novos um ethos de masculinidade marcadamente viril. Isso não significa que não existam masculinidades concorrentes, mas que as alternativas são pouco recorrentes.

A ameaça a essa hegemonia e os conflitos associados a isso dizem respeito a uma questão geracional no sentido de que os jovens, por estarem mais ligados às tecnologias, são considerados menos másculos na comparação com os mais velhos, que aprenderam "pegando no pesado”, numa época em que era necessário se tirar o motor do carro "no braço” e que não havia tantas ferramentas e tecnologias para “facilitar” o serviço. É, portanto, mais homem aquele que aprendeu “na marra”, naqueles tempos áureos quando a força física demarcava mais claramente a posição masculina na relação corpo-ferramenta-carro.

O ofício de mecânico automotivo é atividade exercida por homens e é, em grande medida, uma ocupação que se aprende com avô, pai, tio ou vizinho, na experiência direta do chão da oficina. Nessa transmissão do ofício, não se ensina apenas a dimensão técnica da atividade, mas uma série de lições que passam por visões de modo de vida, representações, concepções políticas e toda uma cultura que identifica o ofício. Trata-se de um processo de construção identitária constante, que envolve saberes, modo de pensar e de fazer. Ser mecânico não diz respeito apenas ao lugar que se ocupa na divisão sociotécnica do trabalho, a uma tradição marcada pela associação entre o ofício de mecânico e uma forma de ser homem.

Os mecânicos são homens e definem a cultura da masculinidade em moldes bastante tradicionais, nos termos de uma "masculinidade hegemônica”, pode-se dizer. As mulheres estão presentes de forma periférica na oficina, às vezes na faxina ou na parte administrativa. A oficina é um espaço para homens.

Neste sentido, a oficina compartilha a mesma condição de outros espaços de sociabilidade masculina. Guedes (1997) analisa alguns desses lugares nos quais se celebra as interações masculinas. Na etnografia que desenvolve em um bairro de classe popular de São Gonçalo (RJ), o autor indica que o clube de futebol é um lugar de homens para homens, que, junto aos bares, botequins e calçadas, definem-se como um território de varões. Guedes (1997) refere-se a esses locais como espaços de jogos no sentido dos jogos de sinuca, carta, futebol, mas 
também num sentido mais abstrato de jogos de virilidade. De modo geral, esses ambientes são interditados às mulheres.

Souza (2003) também se refere a uma dinâmica semelhante ao estudar os encontros para churrascos na esquina de um subúrbio carioca, para ele, área de fronteiras e construção de sociabilidades masculinas. Tudo que se passa nesse lugar, da gestualidade ao vocabulário, são ritos, testes e provas de expressão de uma experiência coletiva de masculinidade e um determinado modo de visibilidade e de status. Não é apenas o churrasco, mas também a partida de futebol, o consumo de álcool e as narrativas sobre façanhas e aventuras sexuais que se imbricam nesses encontros e constituem formas de construção do masculino e de fronteiras de gênero. (SOUZA, 2003)

No caso dos espaços das oficinas mecânicas, também permanecem as interdições para a presença do feminino, mas, dadas as novas dinâmicas do mercado automotivo, procura-se produzir um ambiente que possa ser frequentado por clientes mulheres. Para tanto, investe-se em aspectos simbólicos que contribuam para a descaracterização desse ambiente como um território exclusivamente masculino. Conforme relato de um dos instrutores de cursos profissionalizantes, nos cursos, como conteúdo curricular, “a gente também trabalha a questão de como fazer a oficina quanto à estética, por menor e humilde que seja, organizar uma oficina bem pintada, colocar folhagens... deixar o ambiente mais tranquilo”. (Instrutor, Itec, 2011) ${ }^{8}$ É importante uma boa aparência, uma sala de espera, recepção com revistas, água e outros detalhes que, principalmente, as mulheres e homossexuais apreciam, considera o instrutor.

Com a finalidade de oferecer um tratamento diferenciado às mulheres e homossexuais, que se supõe serem mais interessadas na cortesia, organização e limpeza do que na competência técnica, um dos interlocutores (A. A., 2011) ${ }^{9}$ as presenteia com um brinde (Figura 1), associado, na sua perspectiva, à feminilidade:

8 O Itec, fundado em 1987, é uma das mais importantes escolas de cursos profissionalizantes da cidade de Porto Alegre (RS).

9 Ao longo do texto, os entrevistados são identificados pelas letras iniciais de nome e sobrenome. 
Figura 1 - Chaveiro-brinde para mulheres e homossexuais*

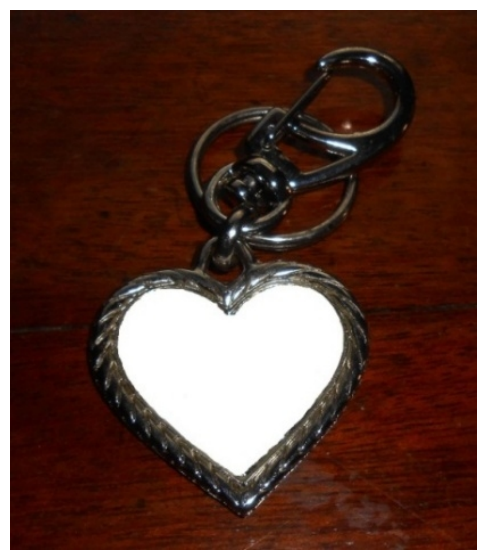

Fonte: acervo do autor (2011).

* O nome da oficina estava no centro do coração e foi ocultado.

É forte o imaginário que associa oficina à masculinidade, acentuando a questão da sexualidade, com destaque para os famosos cartazes de mulheres nuas que, durante muito tempo, povoaram as oficinas - "a oficina antiga que tinha o piso todo sujo, planta de madeira tudo velha, meia dúzia de chaves e um monte de cartaz de mulheres seminuas" (Coordenador pedagógico, Senai-Automotivo, 2010). Mais recentemente, com um processo de maior racionalização e higienização da oficina, tem-se tentado diluir essa relação entre mecânico e assédio às mulheres. As imagens de mulheres nuas praticamente desapareceram das oficinas.

Além desse aspecto, a própria condição sacrificante que existia na oficina do passado é relacionada a algo virtuoso do ponto de vista da virilidade. Considera-se que somente homens másculos poderiam enfrentar as condições tão rudes e adversas que existiam nas oficinas, associadas à sujeira e à necessidade de uso da força física. Antigamente, "as mulheres não queriam nem passar perto de oficina mecânica porque era aquele mecânico sujo, todo engraxado, barbudo, entrava na oficina e era aquele monte de mulher pelada, realmente era pejorativo”. (Gerente-executivo, Sindirepa-RS ${ }^{10}$, 2011) Afirma-se que, hoje, está tudo diferente: “Aquele cara barbudo, aquele macacão com a barriga aparecendo, as mãos engraxadas, aquelas unhas cheias de coisa - hoje em dia não tem mais isso”. (Gerente-executivo, SindirepaRS, 2011)

Aspectos classificatórios da profissão, hoje, considerados estigmas, já foram cultuados como parte do “estilo do ofício”. (FERREIRA, 2013)

Antigamente você ia na oficina, quando eu comecei, se não tivesse dez cartazes de mulher pelada, o dono todo sujo, todo engraxado, graxa até por dentro dos olhos, não tava bom... Mulher não queria nem ver oficina... se a gente não usasse um macacão bem sujo, parece que não tava bom. (A. A., 2011)

10 Sindicato da Indústria de Reparação de Veículos e Acessórios. 
Naquela época, “oficina era tido como um pessoal ignorante, uns graxeiros, e que os caras se contentavam em ter um cartaz de mulher pendurada na parede. O resto era cachaça e cigarro e boemia”. (P.V., 2011) Apesar dos julgamentos negativos, alguns mecânicos fazem questão de se comportar de acordo com o estereótipo associado ao ofício. É como se o ingresso na atividade representasse incorporar determinados símbolos de masculinidade e rusticidade: unhas e mãos engraxadas, uso da força, contação de piada, linguagem sexualizada, entre outros aspectos que correspondem a um determinado habitus e a hexis corporal do ofício.

O habitus - para Bourdieu (2007) - são práticas orientadas por condições passadas de produção e antecipadamente adaptadas as suas exigências, fazendo com que os sujeitos se coloquem em conformidade com as condições sociais anteriores devido a um processo de socialização, que é a incorporação duradoura das maneiras de sentir, pensar e agir do grupo de origem. Assim, evidencia a tendência do grupo em perseverar, assegurando o sucesso da socialização que produz pertencimento. As práticas são harmonizadas para além da busca intencional de coerência, dado o movimento de interiorização das condições objetivas e exteriorização das disposições subjetivas.

Em uma das ocasiões na oficina, durante uma exibição de força, ou, melhor dizendo, em uma demonstração de masculinidade, um dos jovens ergueu uma parte pesada do motor para brincar com a pesquisadora, já que o seu pai havia comentado que não cuidava da coluna. Para o jovem, se escolheu ser mecânico, não pode ter essas “frescuras”. (O. D., 2011)

A exibição de uma masculinidade viril é frequente nesses espaços. Bilate (2014) analisa performances muito semelhantes a partir de uma etnografia realizada em escolas de samba cariocas, a partir da qual discute o processo de construção das identidades sexuais com base na ideia de uma subjetividade corporificada. Um dos aspectos relevantes destacados pelo autor é a reflexão sobre identidade como construção constante, relacional e dependente de determinados contextos. No caso das escolas de samba, o autor se refere a um processo identitário que relaciona corpos e instrumentos musicais, com foco na identidade homossexual masculina nas baterias. O autor traz a noção de performance e de conjuntos relacionais para pensar as identidades sexuais, nas quais corpos e subjetividades estão em constante processo de construção. No caso dos mecânicos, se poderia pensar numa equação semelhante, mas, nesse caso, no lugar dos instrumentos, são corpos, ferramentas e automóveis que compõem um todo nas performances de macheza.

A masculinidade hegemônica está associada às questões de honra, prestígio e direitos e impõe-se a partir de luta por posição, quando se embate com outras masculinidades subalternas. Connell (1987) considera que a masculinidade é relacional, posto que é construída, tendo em 
vista a ideia de feminilidade, de interações sociais e de interdições culturais. Junto à dimensão simbólica, o autor pondera o aspecto físico da corporalidade dos homens. A masculinidade hegemônica é um padrão normatizador que hierarquiza as formas de masculinidade, a partir do qual aquele que não se enquadra (um homossexual, por exemplo) é visto como anômalo e desviante.

As representações de masculinidade e rusticidade associadas aos mecânicos estão para além do dia a dia da oficina. Elas transpassam o imaginário social e circulam pela mídia, como se observa, por exemplo, nos personagens, espécie de "bom selvagem” sensual das novelas da Rede Globo" ${ }^{11}$ Também nos sujeitos reais, espécie de “mau selvagem” imoral, representados nas inúmeras reportagens sobre fraudes em oficinas, envolvendo atividades criminosas ou leso aos clientes, especialmente mulheres ${ }^{12}$, o que, de modo geral, contribui para reforçar a imagem do mecânico enquanto “trapaceiro”.

No sentido de explicar os estigmas que recaem sobre a categoria, alguns indicam elementos que sugerem que as empresas da cadeia da reposição, ao longo dos anos, cultivaram a imagem dos mecânicos como o "selvagem, sexualizado e ignorante”, que, hoje, as propagandas e novelas ainda reproduzem.

A COFAP ${ }^{13}$ era uma que largava aqueles outdoors de mulher pelada... Um dia numa palestra, eu disse assim: se vocês não gastassem dinheiro nisso aí e destinassem esse dinheiro pra criar informação pra nós, vocês podem ter certeza que a oficina ia ser uma outra coisa, porque vocês consideram em primeiro lugar o seguinte: é que todo o mecânico é ignorante... mas nem todo mecânico é ignorante, mecânico não é tarado. Mecânico tem família, tem filho, tem filha... Todas as empresas que eu meti-lhe o pau também nunca mais mandaram cartaz, sumiu. (P.V., 2011) ${ }^{14}$

Nas oficinas frequentadas ao longo da pesquisa, apenas em uma delas, de forma muito discreta, observou-se, ao lado de um rádio, um quadro pintado com uma mulher de biquíni fio dental.

11 Referência aos personagens mecânicos tais como: Pascoal, em Belíssima (Silvio Abreu, 2005); Marcha Lenta, Dagmar, Zidane e Apolo, em Duas Caras (Aguinaldo Silva, 2007); Raí, em Quatro por Quatro (Carlos Lombardi, 1994); Paulão, em A Grande Família (série de TV brasileira, no ar desde 2001); Heitor, em Sol de Verão (Manoel Carlos, 1982), entre outros.

12 Sobre a questão, o Jornal Hoje (Rede Globo) exibe reportagem para demonstrar o quanto o mecânico muda o orçamento dos serviços quando a cliente é mulher. A reportagem foi assistida pelo autor no dia 8 de julho de 2011.

13 Cofap foi uma fábrica de autopeças que teve origem em uma oficina mecânica em São Paulo, de propriedade da família de Abraham Kasinsky, imigrante russa. Desde o início, convencer o mecânico da qualidade das peças e componentes COFAP foi definido como a principal tarefa da empresa. A Cofap instituiu a "Clínica de Doutor em Motores", bastante conhecida no ramo, com o objetivo de formar "doutores" em temas referentes aos serviços. Disponível em: http://www.mmcofap.com.br/ (acesso em setembro, 2016).

14 Os calendários podem até ter "sumido", mas a ideia reproduz-se de outras maneiras. Neste sentido, por exemplo, ocorreu, em uma oficina, o ensaio fotográfico da funkeira Taty Gomes, que posou para a revista Playboy (Edição Especial de Outubro de 2010), reforçando a ideia do espaço da oficina como lugar masculino e sexualizado. Nessa mesma associação da oficina com sexualidade, a famosa Andressa Soares, conhecida como Mulher Melancia, foi capa da Revista Sexy, edição do mês de julho de 2011, e o ensaio também aconteceu em uma oficina mecânica. 
São também associados à ocupação do mecânico esportes como o automobilismo, que, por si mesmo, é uma atividade que promove valores relacionados a uma "masculinidade hegemônica”. A força dos cavalos dos motores se mescla com a força masculina, aproxima os homens dos automóveis, faz deles os cavalos de potência da máquina e, como se a máquina fosse extensão dos seus corpos, esses homens se apropriam dessa força para compor uma versão de virilidade.

Retomando a reflexão de Butler (2003) sobre as composições que lançam mão de ideias acerca do que vem a ser macho ou fêmea, observa-se que a autora desconstrói e reconstrói o conceito de gênero, indo além da binariedade sexo/gênero que entendia o sexo como natural e o gênero como culturalmente construído. Nessa lógica dual, a noção de “destino” se desloca da biologia para a cultura, que produz identidade associada a uma ideia de essência e substância do sujeito, de um "eu” que revela e define de antemão as possibilidades de realizações de gênero.

Para Butler (2003), o tornar-se mulher ou homem não tem uma relação direta com o ter nascido fêmea ou macho. Na complexificação dessas noções, trata-se de superar uma forma de normatização, que está presente em grande medida no heterocentrismo das teorias feministas, mediante o qual, ao contrário do sexo, o gênero é importante. Assim, lança-se mão da reflexão sobre as possibilidades de viver as masculinidades, feminilidades e sexualidades sem estar aprisionado a marcações biológicas, dado que muitas pessoas não se identificam com padrões binários de gênero. Para a autora, o corpo físico, portanto, não define nem gênero nem sexualidade. O pensamento queer é antinormativo e vai além da binariedade, dado que há muitas performances de gênero que não se enquadram e são - em maior ou menor medida transgressoras.

No caso dos mecânicos, esses binários se colocam com ênfase, e as ameaças a eles são contidas. É o caso de um dos interlocutores, que era mecânico e tentou ser cabeleireiro aos finais de semana. A atividade fazia dele alvo de piadas e deboches constantes por desempenhar uma tarefa que cruzou a fronteira do viril, ao trocar a chave de fenda e a graxa pela tesoura e o creme de cabelo.

O imaginário que associa o mecânico a uma figura máscula é cotidiano e se compõe desde o ingresso no ofício e incorporação do habitus do grupo profissional. Há uma espécie de moralidade viril que envolve a condição de mecânico. Trata-se de um tipo de homem desleixado com a aparência, barbudo, forte, que usa camisa mostrando o peito e os músculos, macacão sujo de graxa, piadista, repleto de aventuras de sexualidade, hábil em assediar mulheres, entre outros elementos que compõem o "kit homem”. É da ordem de uma “masculinidade hegemônica” que, sob vários aspectos, não coincide com a condição real de boa parte desses sujeitos, contudo, 
permanece hegemônica, justamente porque serve de modelo e reprime masculinidades subalternas e outras "masculinidade de protestos".

Para Bourdieu, determinadas categorias de classificação espelham o mundo masculino e permitem a reprodução do habitus. Naturalizam-se os comportamentos de homens e mulheres, com base em uma cosmologia falocêntrica:

Cabe aos homens, situados do lado exterior, do oficial, do público, do direito, do seco, do alto, do descontínuo, realizar todos os atos ao mesmo tempo breves, perigosos e espetaculares, como matar o boi, a lavoura, a colheita, sem falar do homicídio e da guerra, que marcam rupturas do curso ordinário da vida. As mulheres, pelo contrário, estando situadas do lado úmido, do baixo, do curvo e do contínuo, vêm ser-lhe atribuídos todos os trabalhos domésticos, ou seja, privados e escondidos ou até menos invisíveis e vergonhosos. (BOURDIEU, 1999, p. 41)

A construção da masculinidade passa pelo corpo dos homens, quer dizer, o sexo masculino é lapidado para a produção de um ideal de gênero. As categorias de percepção, que se constroem a partir do habitus, classificam os homens e seus corpos e são classificadas por eles. Aprende-se a ser homem, assim como Simone de Beauvoir afirmou que se aprende a ser mulher, e, mais do que isso, aprende-se que as masculinidades concorrentes baseadas em sexualidades e desejos alternativos precisam ser controladas - poderiam generalizar-se e ameaçar a ordem das coisas se não o fossem? -, sob pena de ameaçar as idealizações dos modelos viris.

Esses rituais de virilidade passam pelo corpo e lançam mão de uma expressão fálica, como no caso - usual ao estereótipo associado aos mecânicos - de coçar com frequência os genitais, uma reação corporal que nunca se sabe, com certeza, se decorre de algum desconforto momentâneo ou se é uma forma de se comunicar que homens viris costumam agir dessa forma. Tais aspectos à luz da teoria queer levam a indagar acerca dos processos educacionais e de sociabilidade heteronormativa que marcam uma heterossexualidade compulsória e normalizadora que enquadra uma suposta natureza de macho.

Conforme Miskolci (2012), na sexualidade - que envolve desejo, afeto e intimidade -, a sociedade encontra um meio de normalização, o que, com frequência, ocorre por meio de injúrias, chacotas, xingamentos, humilhação, produção de vergonha, invisibilidade e não reconhecimento - quando não violência contra aqueles de gênero não esperado. Trata-se de uma cultura de binários - construída em diferentes instâncias, com destaque para o campo educacional -, que restringe as inúmeras expressões de afeto e sexualidade. Verifica-se, assim, imposição de modelos comportamentais e gramáticas morais que padronizam as identidades e produzem a classificação e o julgamento de algumas pessoas como abjetas, em relação as quais se sente repulsa. A ideia do normal pressupõe o anormal e o inferior e, nesses termos, ser homem ou mulher é a única alternativa padrão. 
A oficina é espaço de sociabilidade masculina, assim como o são os espaços de lazer correlatos a ela, como vem a ser o caso do automobilismo. No cotidiano desses espaços, está autorizada uma determinada maneira de viver a experiência como homem. Os outros corpos que circulam por ali - como os dos gays que cruzam a porta de entrada da oficina- servem de pretextos para o reforço de uma versão estética, gestual e linguística da forma de ser macho que se atualiza cotidianamente como expressão de consciência de que não é a única possível. Sobre os espaços para o cultivo de uma narrativa do masculino, segundo Connell e Messerschmidt (2013, p. 263):

O consenso cultural, a centralidade discursiva, a institucionalização e a marginalização ou a deslegitimação de alternativas são características amplamente documentadas de masculinidades socialmente dominantes. Também, muito apoiada, é a ideia original de que a masculinidade hegemônica não necessita ser o padrão comum na vida diária de meninos e homens. Em vez disso, a hegemonia trabalha, em parte, através da produção de exemplos de masculinidade (como as estrelas dos esportes profissionais), símbolos que têm autoridade, apesar do fato de a maioria dos homens e meninos não viver de acordo com eles. (CONNELL; MESSERSCHMIDT, 2013, p. 263)

O automobilismo brasileiro é conhecido por meio da história dos pilotos e é uma atividade favorável para a reflexão sobre masculinidade. Todos os brasileiros já ouviram falar em Ayrton Senna e muitos acompanham as corridas da Fórmula 1. O piloto Senna representou a modernidade brasileira (WOLFE, 2010) da mesma forma que o automóvel foi associado ao progresso, desenvolvimento econômico e a entrada da nação no mundo moderno. Essa perspectiva é reforçada pela indústria automotiva brasileira, criada na década 1950. Também o censo dos automóveis passou a ser considerado uma medida da modernidade brasileira (WOLFE, 2010), uma vez que o automóvel prometia mudar o padrão de desenvolvimento brasileiro. Por isso, o presidente Washington Luís (mandato de 1926-1930) declarou, em 1926, que governar era abrir estradas, que integrariam fisicamente o Brasil como nação. O carro, portanto, era uma ferramenta que poderia unir o Brasil e fazer do país uma nação moderna.

Pierre Lesdain, francês chegado no Rio de Janeiro em 1908, junto com três mecânicos, viajou 34 dias do Rio de Janeiro até São Paulo. No final da corrida, afirmou que o Brasil precisava construir uma estrada conectando ambas as cidades. (WOLFE, 2010) Conforme Wolfe (2010), a primeira corrida de carros registrada na América do Sul foi em São Paulo, em 1908, quando as pessoas conheceram o poder da velocidade e da tecnologia.

O automobilismo é um esporte cultivado pelo gosto masculino. Bourdieu (2007) indica que o gosto serve como esquema social de classificação, com acesso parcial à consciência. Operador prático que transforma obrigações em preferências e engendra as escolhas que constituem estilos de vida classificados e classificantes. "Necessidade tornada virtude... levando 
a 'escolhas' ajustadas à condição de que ele é o produto”. (BOURDIEU, 2007, p. 166) Dito de outro modo, “o gosto é amor fati, escolha do destino”, é “cultura tornada natureza”.

O corpo manifesta a objetivação do gosto, ou seja, mesmo o que parece mais natural é social. O corpo é a maneira de tratá-lo, alimentá-lo, andar. Trata-se de esquema corporal, uma maneira de posicionar o corpo que expressa modos de ser e estilo de vida. Tal sistema de diferenças está associado à maneira que se distribui a estrutura do consumo: alimentação, cultura, despesas com apresentação e representação de si (cuidados corporais, saúde, beleza, vestuário), apontando para o estado de distribuição dos bens e das práticas. Desse modo, pensase o corpo e o gosto como produto da cultura, posto que envolve percepção (força, saúde, forma) e fabricação cultural, tendo, como efeito, distinguir grupos. O corpo parece estar baseado na natureza, mas as propriedades corporais são apreendidas. O esquema corporal é depositário de uma visão de mundo. Na prática, o gosto passa pela socialização, experiência, trajetórias culturais e processo educativo (família e escola); não é inato e gera determinadas competências culturais/patrimônio cognitivo.

O automobilismo, há muito tempo, associa-se ao gosto dos homens pelos carros e ao fascínio pelo ronco dos motores. No caso da cidade de Porto Alegre, o esporte começou nas ruas e, com o tempo, foi sendo circunscrito ao autódromo da cidade, onde acontece tanto grandes circuitos como a prática do automobilismo popular.

Nos dias de competição dos carros populares, no autódromo, tem churrasco, cerveja gelada e caipirinhas. O lugar vira uma festa. O espaço das corridas é local de encontro para os que seguem esse circuito. Os jovens andam de um lado para o outro, paquerando, e alguns dançam nos embalos das músicas que tocam entre uma corrida e outra. É um espaço de exibição e afirmação da masculinidade, pois, mesmo os que não estão correndo, estão ali para atrair as garotas com o som dos motores dos seus carros.

A maioria dos “veteranos” da mecânica, pelo menos, em algum momento das suas vidas, envolveu-se com carro de competição. Um dos interlocutores já obteve vários troféus como preparador. O mais recente foi o troféu do Campeonato Gaúcho, apresentado na Figura 2. 
Figura 2 - Melhor preparador de carros de corrida

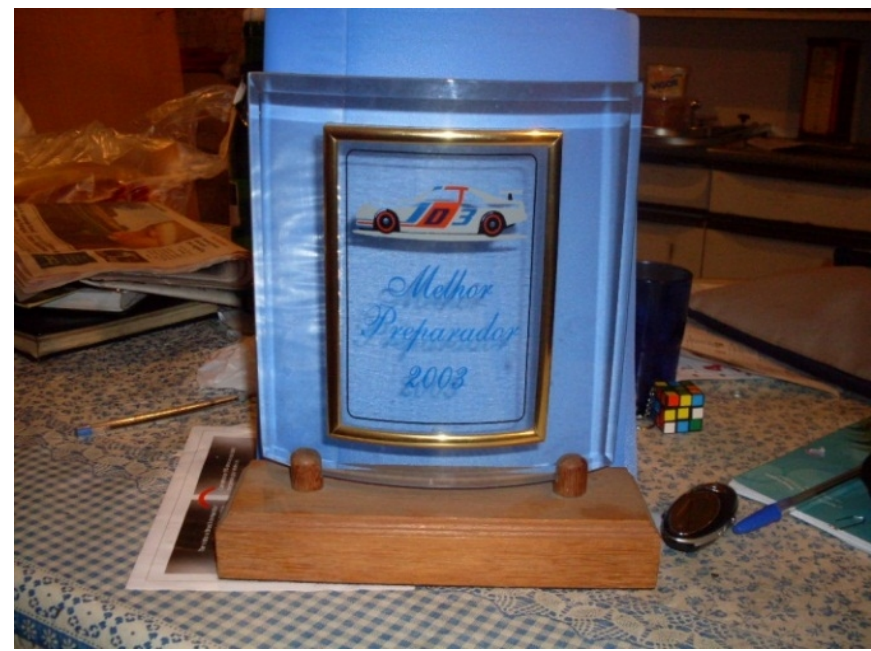

Fonte: acervo do autor (2011).

Ao lado dos "veteranos", muito dos “novatos" herdam o gosto pelo automobilismo. Esse é um espaço onde carros, corridas e homens se retroalimentam na construção de atividades que são “coisa de homem”.

O autódromo internacional de Tarumã, em Viamão, município a 30 km de Porto Alegre, foi inaugurado em 1970. Antes disso, quando o Automóvel Clube do Rio Grande do Sul foi fundado, em 1949, as corridas eram realizadas nas ruas e estradas do estado. Hoje, Tarumã é uma das mais tradicionais pistas do automobilismo nacional. O Campeonato Gaúcho de Automobilismo e outros realizam suas provas na pista de Viamão. Tarumã também é sede de eventos nacionais como os campeonatos brasileiros de Fórmula Truck, Stock Car, Fórmula Renault, Pick Up Racing, entre outros. O autódromo é ainda sede do Racha Tarumã (quando os motoristas desafiam uns aos outros para exibir a velocidade dos seus carros), que acontece todas as sextas à noite desde 1997.

Em dias de racha, o movimento é intenso. Na oportunidade em que se frequentou as corridas, os rachas começavam às 22 horas e, às 2 horas, acontecia o show das cadeiras elétricas. $\mathrm{Na}$ "cadeira elétrica”, sorteia-se a chance de as pessoas do público acompanharem os pilotos em manobras radicais em alta velocidade. Todos ali passam o tempo todo com os ouvidos atentos no empolgante ronco dos motores. É um espetáculo das máquinas, mas também um espetáculo de masculinidade, com direito a menu completo: carros, velocidade, churrasco, cerveja e mulheres. Próximo à arquibancada, há quiosques vendendo lanches e bebidas. Ao lado dos quiosques, ficam umas churrasqueiras de chão, onde o público pode chegar à vontade para assar uma carne, um churrasco. Esse é um grande ponto de encontro de jovens. 
Os mecânicos preparadores são também corredores, o que eles fazem tanto pela renda como pelo gosto pelo automóvel. Em uma das oficinas observou-se 41 troféus que os mecânicos, dois irmãos, ganharam em corrida. Um deles ganhou o troféu Catarino Andreatta. Andreatta correu muitos anos, por volta das décadas de 1960 e 1970. Na recepção da oficina, também havia uma série de fotos dos carros de corrida. Na ocasião da visita, a esposa de um dos mecânicos lembrou que, quando o marido era jovem, ele e o irmão, também mecânico, passavam até madrugada preparando carros e, depois, no final de semana, iam para as corridas. "A gente perdia os maridos pra corridas”, disse ela, sem muito incômodo. Um dos irmãos ainda corre e está ligado, como piloto, à Federação do Automobilismo. Ele explicou que existe um teste feito pela federação e aquele que passar pode ser piloto. Considera-se um apaixonado por carros e afirma que “o automobilismo é o esporte do mecânico”.

Conta-se que, nas corridas de antigamente, o mecânico corria junto com o piloto, porque tinha que ir consertando o carro durante o percurso, que acontecia em estradas de chão batido e os carros quebravam o tempo todo. Além disso, eles faziam peças, soldavam, fabricavam parafuso, sendo esse um processo fundamentalmente artesanal. Quando se refere ao automobilismo no Rio Grande do Sul, de imediato surgem grandes nomes da época das carreteiras: os galgos brancos; os dois irmãos, Julio e Catarino José Asmuz. Todos eles tinham seus mecânicos ${ }^{15}$.

O automobilismo mexe muito com o espírito de competitividade dos homens. O domínio da área de competição é fonte de orgulho e status nesse setor: "Em geral, poucos mecânicos têm estudo em cima da mecânica, e muitos menos ainda têm conhecimento para área de competição, para trabalhar num nicho de mercado que parte do princípio de aumentar potência do carro original”. (L. R., 2011)

A questão do orgulho dos preparadores é uma constante: “Eu vou te dizer uma coisa. Eu já fui muito arrogante na minha vida. Quando eu comecei a fazer os carros de corrida, aquilo subiu muito na minha cabeça. Eu achava que eu era o cara de tudo”. (M. M., 2011) A competição entre os mecânicos ocorre através dos carros e por meio da disputa por saberes. Um dos interlocutores destaca que carro preparado por ele já ganhou de carro que engenheiro, com muito mais dinheiro, havia preparado, revelando essa disputa: “No meio dos preparadores, cada um é o melhor que existe. A autoestima está dez vezes maior que o conhecimento”. (L. R., 2011)

A competição envolve gosto: "Sempre gostei muito de carro de competição. Está meio que no sangue”. (O. D., 2011) O filho desse interlocutor, que acompanhava a entrevista, afirmou: “Eu adoro competição também”. Isso porque, destaca o pai: “Desde criança, ele se 
criou dentro de um carro de corrida". O envolvimento com as corridas acaba sendo uma atividade em família, com os mecânicos preparadores incentivando os filhos homens no esporte. Ademais, sobre essa dimensão do gosto, destaca-se: “Minha vida é carro, eu sempre gostei de carro, dos tempos das corridas... É claro que eu gostaria de ser só um corredor profissional, piloto de corrida, mas como também não consegui, então, pelo menos isso aí me atrai... No fim, eu fiquei nesse segmento”. (J.O., 2011)

Verifica-se o esforço, a competição e o desafio como narrativa de masculinidade:

A aprendizagem ocorria na base da tentativa e erro, pois, na época, não tinha aparelhamento... Eu trabalhei muito em carreteira, aprendi muito, porque, na corrida, é que tu aprende a ser eficiente. O cara tá correndo, e a corrida é de quem está na frente. Se acontece alguma coisa no carro, ele vai para no box, se está falhando um cilindro, se ele não tem mais força, tu tem que raciocinar rápido e ir no defeito, ali que tu aprende a fazer um diagnóstico rápido, isso eu aprendi muito nas corridas de automóvel. (E. S., 2011)

Numa outra oficina, o mecânico exibe na parede a foto de um carro seu e diz o seguinte:

Ele teve um recorde absoluto de Tarumã. Ganhou todas as provas. Largou em primeiro sempre. Aí, todos os anos tinha uma coisa que não era muito legal. Os preparadores votavam para indicar quem era o preparador do ano, e, nesse tipo de coisa, tu vem fazendo inimizade. Não pensa que todo mundo te adora. Envolve muita competição. (O. D., 2011)

Mais do que uma fonte de renda, a preparação de carros de corrida envolve toda uma forma de sociabilidade. Nos relatos, conta-se que, muitas vezes, trabalhava-se na mecânica com a intenção de poder sustentar as corridas:

Eu precisava de dinheiro para correr nos carros, na verdade, eu comecei a trabalhar pra poder correr. Então, eu pegava de outros corredores, eu dizia 'não, eu faço', eu comecei a fazer carros de corrida, preparar motor, montar o carro, fazia carro de corrida cobrando. Eu tinha, na verdade, uma oficina na garagem do meu edifício, mas, depois de um tempo, o síndico me expulsou de lá, mas quanto tempo durou, foi onde eu fiz dois Chevettes, na época, um era pra mim pagar minhas corridas, e assim foi indo. (J. O., 2011)

Durante a pesquisa, teve-se a possibilidade de entrevistar um interlocutor que foi mecânico, piloto e dirigente de automobilismo:

Comecei, como eu sempre digo, correndo de automóvel e terminei como presidente do conselho técnico desportivo nacional, que dirige todo o Brasil. Me orgulho de duas coisas. A primeira carteira do seu Ayrton Senna, pra correr internacionalmente, fui eu que assinei, eu e seu Nelson Piquet também, como presidente do Conselho... Era responsabilidade do presidente do conselho assinar as carteiras de piloto, e eles tinham que prestar um exame, e nós tínhamos que avaliar. (G. S., 2011) 
Esse conselho "hoje é a Confederação Brasileira de Automobilismo. E o órgão que dirige o conselho é o conselho técnico desportivo nacional. Fui presidente da federação gaúcha de automobilismo”. (G. S., 2011)

A admiração por Ayrton Senna é generalizada - espécie de patrimônio da categoria - e está acima de qualquer referência ao estilo de masculinidade do piloto. Senna estava longe de uma performance viril. Ele tinha uma fala mansa, jeito de andar suave e enfrentou uma série de controvérsias públicas sobre a sua sexualidade. Com frequência, surgiram polêmicas e suspeitas sobre ser gay e sobre os romances com as mulheres serem meras fachadas. Independentemente de quem era ou não Senna em relação à sexualidade, o relevante aqui é que a suspeita decorresse justamente a partir de um determinado pressuposto heteronormativo de performance de gênero, ainda mais relevante por ele ter estado vinculado ao mundo do automóvel, um espaço feito por homens e para homens, por assim dizer.

Para os homens, atraídos pelo fascínio da tecnologia automotiva, a oficina, sem dúvida, é fonte de renda, mas significa algo maior: “A minha vida foi isso”. (E. S., 2011) É o lugar onde se repara carro, mas pode ser também, no caso das independentes, o local onde se cria os filhos, convive com a esposa, namorada, e encontram-se os amigos, o que faz da oficina um espaço de sociabilidade. Certa vez, a esposa de um dos mecânicos relatava - e reclamava - que, aos finais de semana, a oficina fica cheia de homens que vêm para passar a tarde em volta dos carros, conversar e tomar chimarrão, o que atrapalha sua rotina com o marido.

Essas, entre outras narrativas, trazem à tona a relação que se estabelece entre o ofício do mecânico e as práticas de masculinidade, entre as quais se destaca o automobilismo, que funciona como espaço de trabalho e lazer entre os mecânicos. Mais do que isso, é um dos eixos a partir do qual se constitui uma sociabilidade masculina, por meio de uma socialização que se dá ao redor dos motores.

\section{Considerações finais}

A essa simbiose, entre ofício de mecânico e masculinidade hegemônica, somam-se dois aspectos: o fato de serem homens de origens marcadamente associadas à cultura popular, bem como ao fato de serem gaúchos. (LEAL, 1992) Todos os aspectos corroboram para a sustentação de concepções e atitudes associada a uma masculinidade hegemônica.

A socialização no ofício de mecânico envolve formação, memória, subjetividade, cultura, ética e versões da masculinidade. Narra-se a própria forma de conceber a vida quando se elabora a identidade de trabalhador e de homem nessa atividade. Uma socialização masculina que se entrelaça com uma formação laboral. Trata-se de interações cotidianas nas quais se transmite o 
todo de uma experiência laborativa. Esses trabalhadores, em seu processo de autoconstrução, produzem sua condição de homens de classe trabalhadora, constroem seus corpos laborais e uma determinada identidade masculina.

A oficina, como território de masculinidade, é local de expressão do "estilo de ofício" (FERREIRA, 2013), que, observado do ponto de vista de gênero, evidencia que o mundo do trabalho está entrelaçado com o universo da cultura e sempre envolve um modo de vida, do qual a construção de gênero é componente indissociável.

\section{Referências}

BILATE, L. F. Homossexualidades masculinas em baterias de escolas de samba: sobre a relacionalidade das identidades. Cronos, Natal, v. 15, n. 1, p. 157-174, 2014.

BOURDIEU, P. A distinção: crítica social do julgamento. Porto Alegre: Zouk; São Paulo: Edusp, 2007.

BOURDIEU, P. A dominação masculina. Rio de Janeiro: Bertrand Brasil, 1999.

BUTLER, J. Problemas de gênero: feminismo e subversão da identidade. Rio de Janeiro: Editora Civilização Brasileira, 2003.

CERTEAU, M. A invenção do cotidiano: artes de fazer. Petrópolis: Vozes, 2008.

CONNELL, R. Masculinities. Berkeley: University of California Press, 1987.

CONNELL, R.; MESSERSCHMIDT, J. Masculinidade hegemônica: repensando o conceito. Estudos Feministas, Florianópolis, v. 21, n. 1, p. 241-282, 2013.

COSTA, S. G. A crise da masculinidade: uma crítica à identidade de gênero e à literatura masculinista. Psicologia Ciência e Profissão, Brasília, DF, v. 26, n. 1, p. 118-131, 2006.

FERREIRA, L. S. Processos de resistência e novos desenhos identitários: o ofício do mecânico e a racionalização da indústria da reparação automotiva. 2013. Tese (Doutorado em Sociologia) Universidade Federal do Rio de Janeiro, Rio de Janeiro, 2013.

FIGLIUZZI, A. Homens sobre rodas: representações de masculinidades nas páginas da revista Quatro Rodas. 2008. Dissertação (Mestrado em Educação) - Universidade Federal do Rio Grande do Sul, Porto Alegre, 2008. 
GINZBURG, C. O queijo e os vermes: o cotidiano e as ideias de um moleiro perseguido pela inquisição. São Paulo: Companhia das Letras, 2006.

GUEDES, S. L. Jogo de corpo: um estudo de construção social de trabalhadores. Niterói: EDUFF, 1997.

HONÓRIO, M. D. Cabra-macho, sim senhor! Um estudo sobre a masculinidade no Nordeste do Brasil. In: CONGRESSO BRASILEIRO DE SOCIOLOGIA, 15., 2011, Curitiba. Anais [...]. Porto Alegre: Sociedade Brasileira de Sociologia, 2011.

LEAL, O. F. Suicídio, honra, morte e masculinidade na cultura gaúcha. In: ORO, A.; TEIXEIRA, S. Brasil \& França: ensaios de antropologia social. Porto Alegre: UFRGS, 1992. p. 141-150.

LOURO, G. L. Uma política pós-identitária para a educação. Estudos feministas, Florianópolis, v. 9 n. 2. 2001.

MISKOLCI, R. Teoria queer: um aprendizado pelas diferenças. Belo Horizonte: Autêntica, 2012.

SCOTT, J. Gênero: uma categoria a útil de análise histórica. Revista Educação e Realidade, Porto Alegre, v. 20, n. 2, p. 133-184, 1995.

SOUZA, R. R. A confraria da esquina: o que os homens de verdade falam em torno de uma carne queimando - etnografia de um churrasco de esquina no subúrbio carioca. 2003. Dissertação (Graduação em Ciências Sociais) - Universidade do Estado do Rio de Janeiro, Rio de Janeiro, 2003.

WOLFE, J. Auto and progress: the Brazilian search for modernity. New York: Oxford University Press, 2010. 